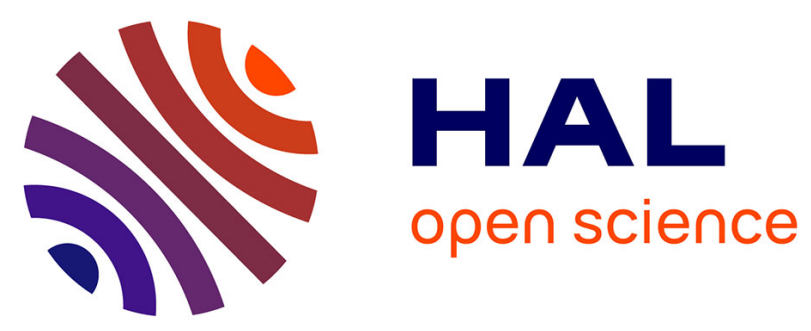

\title{
Ivabradine: A promising drug in cardiogenic shock to prevent the undesirable sinus tachycardia induced by dobutamine?
}

Benoit Lattuca, François Roubille

\section{- To cite this version:}

Benoit Lattuca, François Roubille. Ivabradine: A promising drug in cardiogenic shock to prevent the undesirable sinus tachycardia induced by dobutamine?. International Journal of Cardiology, 2015, 178, pp.308 - 310. 10.1016/j.ijcard.2014.09.106 . hal-01761284

\section{HAL Id: hal-01761284 \\ https://hal.umontpellier.fr/hal-01761284}

Submitted on 6 Nov 2018

HAL is a multi-disciplinary open access archive for the deposit and dissemination of scientific research documents, whether they are published or not. The documents may come from teaching and research institutions in France or abroad, or from public or private research centers.
L'archive ouverte pluridisciplinaire HAL, est destinée au dépôt et à la diffusion de documents scientifiques de niveau recherche, publiés ou non, émanant des établissements d'enseignement et de recherche français ou étrangers, des laboratoires publics ou privés. 


\section{Ivabradine: A promising drug in cardiogenic shock to prevent the undesirable sinus tachycardia induced by dobutamine?}

Keywords:

Heart failure

Dobutamine

Cardiogenic shock

Ivabradine

Severe systolic Heart Failure (HF) and especially the ultimate form represented by cardiogenic shock are associated with a very poor prognosis including a very high in hospital mortality. Inotropic drugs are until now the cornerstone of the management of cardiogenic shock. By contrast, both guidelines from the ACC/AHA and ESC recommend limited use of the inotropic agents for the management of acute $\mathrm{HF}[1,2]$. Indeed, on the one hand these drugs exert a dose dependent inotropic and chronotropic positive effect leading to cardiac output increase and left ventricle (LV) filling pressures decrease, but on the other hand they expose to side-effects such as particularly induced sinus tachycardia that may in turn induce detrimental myocardial ischemia and arrhythmias and importantly as regards pathophysiology sinus tachycardia prevents efficient filling through shortened diastole [3]. Paradoxically, even if tachycardia is known to reduce diastole duration being then deleterious in this clinical setting, it is also usually considered as a compensatory mechanism deserving to be respected. Although theoretically logical, this common belief should be challenged.

Furthermore, although the effect of inotropic drugs is not established with regards to mortality, they are paradoxically given in life-threatening situations. These patients have a poor prognosis and specific clinical trials are extremely difficult to initiate.

Ivabradine has been found to specifically block hyperpolarizationactivated cyclic nucleotide-gated (HCN) channels without any effects on other receptors or channels in the cardiovascular system, at therapeutic concentrations (see Fig. 1 for schematic presentation of the mechanisms and see for review [4]). Ivabradine inhibits the If funny current (supported by the HCN channels), an ionic current involved in pacemaking activity in the sinoatrial node. $\mathrm{HCN}$ channels are specifically expressed in the heart and the central nervous system and ivabradine reduces heart rate (HR) without depressing myocardial contractility or reducing cardiac output $[5,6]$.

As regards HF, ivabradine is recommended (class Ila, level B) in chronic stable HF in patients in sinus rhythm with a left ventricular ejection fraction (LVEF) $\leq 35 \%$, an $\mathrm{HR} \geq 70 \mathrm{bpm}$, and persisting symptoms (NYHA classes II-IV) despite treatment with an evidence-based dose of $\beta$-blocker (or maximum tolerated dose below that), angiotensinconverting enzyme inhibitor (or angiotensin II receptor blockers), and

\footnotetext{
A comment on the paper "hemodynamic effects of ivabradine in addition to dobutamine in patients with severe systolic dysfunction".
}

a mineralocorticoid receptor antagonist [2]. Nevertheless, due to lack of data, ivabradine remains until now contra-indicated in case of acute HF and cardiogenic shock, as these situations were considered as exclusion criteria in almost all clinical trials.

Noteworthy, ivabradine has just been reported to potentially exert detrimental effects in another indication (coronary artery disease) and there will be further investigations.

Taking all these considerations together, it could be promising to introduce ivabradine carefully to obtain a selective decrease in HR, with no impact on output and contractility parameters (Fig. 2). This new strategy may improve LV relaxation, decrease oxygen needs and further facilitate inotropic drugs including dobutamine weaning.

Preliminary data supporting this hypothesis are scarce. Experimental data have suggested for decades that ivabradine could exert positive hemodynamic effects in dogs [7]. More importantly the drug has been shown to exert favorable impact on HF including the lowest LV ejection fraction in the main study [8] and some clinical cases are reported [3,9]. More precisely in advanced HF, a small trial in 10 patients has assessed the hemodynamic effects of ivabradine in patients with advanced HF and markedly depressed LV function (LVEF $21+/-7 \%$ ). Ivabradine $0.1 \mathrm{mg} / \mathrm{kg}$ was infused and hemodynamic effects were carefully monitored. Ivabradine significantly reduced HR, by a maximum of $27 \%$ at $4 \mathrm{~h}$, increased stroke volume and LV systolic work by a maximum of $51 \%$ (to $66+/-17 \mathrm{ml}$ ) and $53 \%$ (to $58+/-20 \mathrm{~g}$ ) at $4 \mathrm{~h}$. No serious adverse events occurred [10]. Beyond the acute impact in severe acute $\mathrm{HF}$, favorable LV remodeling could also be hoped as reported in an echocardiographic substudy of the Shift trial [11].

In this issue, Gallet et al. reported promising data in the manuscript entitled "hemodynamic effects of ivabradine in addition to dobutamine in patients with severe systolic dysfunction" [12]. They proposed a double approach: 1 /they assessed first the effects of Ivabradine in addition to dobutamine in stable HF patients $(\mathrm{LVEF}<35 \%, \mathrm{n}=22$ ) in whom they assessed both systolic and diastolic function at rest and under dobutamine [10 $\gamma / \mathrm{min}$ ], before and after Ivabradine [5 $\mathrm{mg}$ per os]; and 2 /they validated the effects of dobutamine in patients with refractory cardiogenic shock ( $n=9$, validation population) with contraindication to cardiac assistance or transplant. In this latter population, ivabradine [ $5 \mathrm{mg}$ twice a day] was added to the dobutamine infusion. The authors obtain here promising results. 1/In the first population, ivabradine decreased HR as expected. More importantly this decrease was associated with a decrease in cardiac power output and an increase in diastolic duration, an improvement in LVEF in both situations. 2/In the validation population, ivabradine improved diastolic filling time without decreasing cardiac output. At $24 \mathrm{~h}$, ivabradine improved systolic blood pressure, daily urine output, oxygen balance and NT-proBNP. Conclusions on events are obviously difficult to draw, in regard to the very small number of patients. Anyway, they establish in this pilot study the safety and potential benefit of an HR lowering agent in cardiogenic shock. This seems all the more promising as such studies in patients suffering from a severe HF associated with very poor clinical outcomes are extremely difficult to initiate and complete. Secondly, 


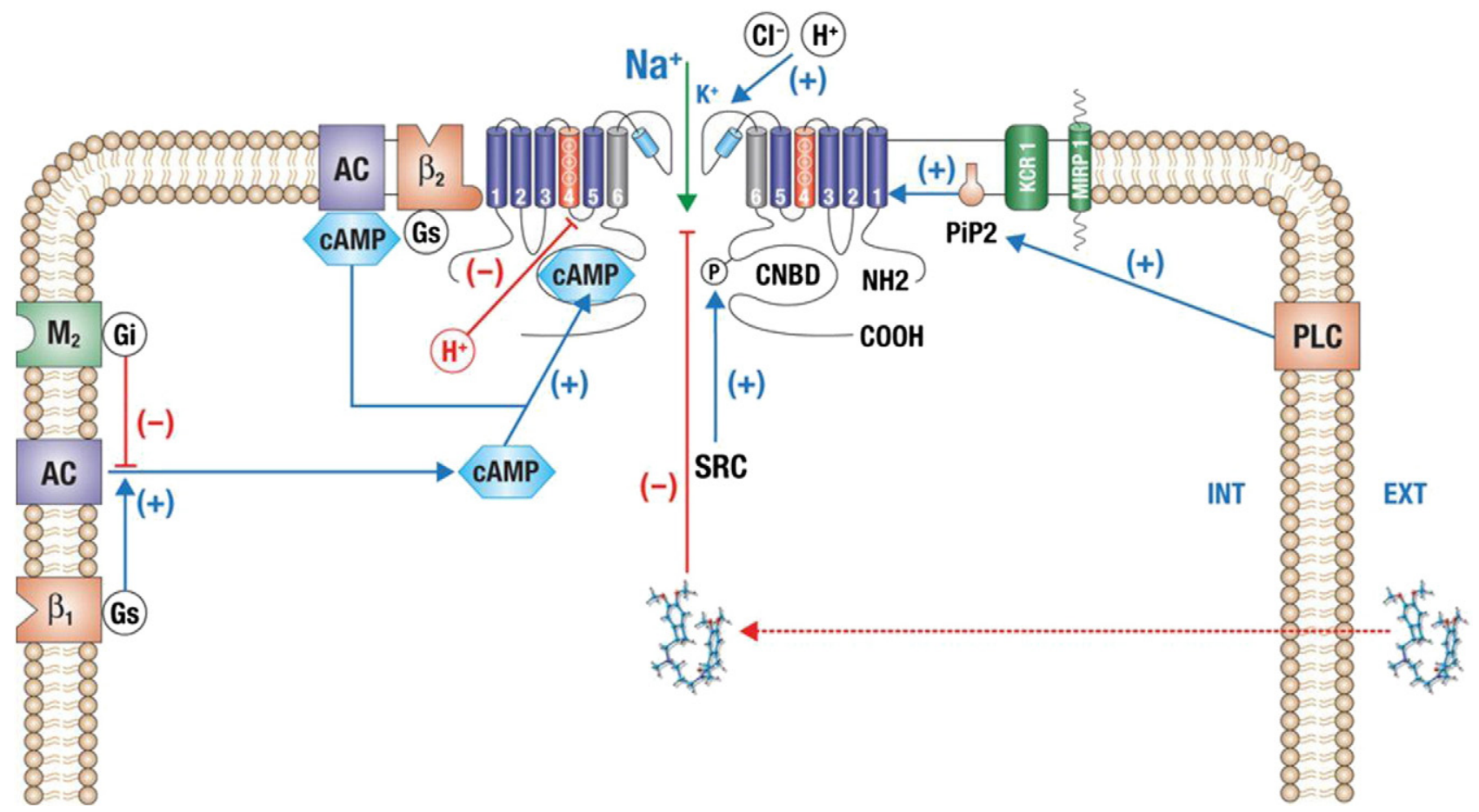

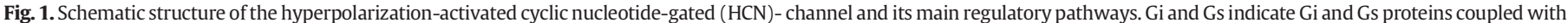

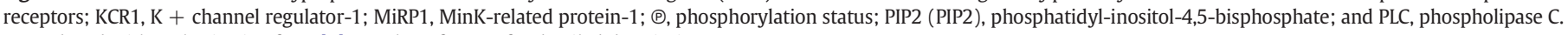
Reproduced with authorization from [4]. See the reference for detailed description.

severe HF with contra-indication for heart transplantation or assistance is not exceptional but remains until now deadlocked. Nevertheless, this study presents limitations as recognized by the authors. They chose to study two distinct populations and provided then accurate and consistent data but the design is a bit unusual. Beyond technical discussions, the open design and above all the very small number of patients prevent to conclude definitely. Some characteristics of the population prevent also from comparing to other ones, such as the very poor adherence to

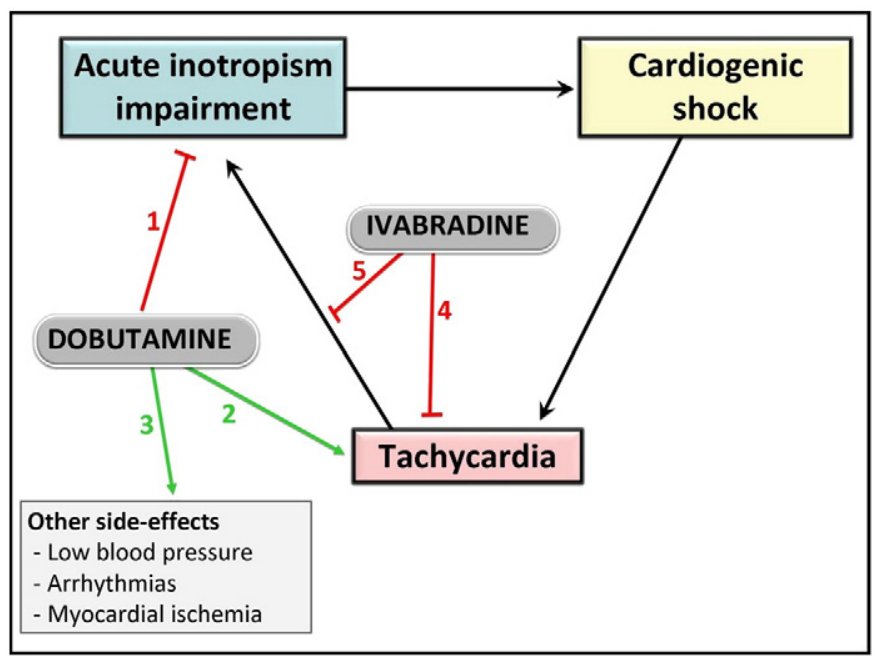

Fig. 2. Schematic presentation of the theoretical interest of ivabradine in cardiogenic shock. Initial contractility and inotropism failure leads to cardiogenic shock and induces compensatory mechanisms such as increased heart rate to maintain effective cardiac output. As a side effect, this compensatory phenomenon results in an increase in oxygen consumption and decrease of systolic ejection volume, leading to a vicious circle. On the one hand, the introduction of dobutamine could restore inotropism [1]. On the other hand it could participate in tachycardia leading to diastolic impairment [2,3]. The combined use of a pure heart rate lowering agent such as ivabradine would limit this increase in heart rate and then break the vicious circle [4,5]. treatments (until half of the patients are contra-indicated to transplantation for this reason).

To our mind, only few trials are currently addressing this important issue. Only two studies are referenced in the clinicaltrials.gov for instance with the keywords "ivabradine" and dealing with severe HF. The first one is a phase II mechanistic study in few patients (NCT00202579). The second one is a study in patients with multiple organ dysfunction syndrome (MODS, NCT01186783) [13]. Results of this latter study should be published soon.

In conclusion, results presented here are promising and deserve fully to be confirmed or not through large multicenter trials. Although a strict PROBE design could be difficult in such settings, simultaneous exhaustive biological, imaging and hemodynamic assessments should be carefully designed and above all long clinical follow-up remains mandatory. The very question seems to be whether this new approach could offer better survival and not beyond an acute and transient hemodynamics support, which is already the case regarding inotropic agents. Importantly, recent results (the SIGNIFY trial) urge the careful monitoring of adverse events.

\section{Conflict of interest}

The authors report the following conflict of interest: FR has received honoraria for lectures and research grants from Servier.

\section{References}

[1] Hunt SA, Abraham WT, Chin MH, Feldman AM, Francis GS, Ganiats TG, et al. 2009 Focused update incorporated into the ACC/AHA 2005 guidelines for the diagnosis and management of heart failure in adults: a report of the American College of Cardiology Foundation/American Heart Association task force on practice guidelines: developed in collaboration with the International Society for Heart and Lung Transplantation. Circulation 2009;119:e391-479.

[2] McMurray JJ, Adamopoulos S, Anker SD, Auricchio A, Bohm M, Dickstein K, et al. ESC guidelines for the diagnosis and treatment of acute and chronic heart failure 2012: the Task Force for the Diagnosis and Treatment of Acute and Chronic Heart Failure 2012 of the European Society of Cardiology. Developed in collaboration with the Heart Failure Association (HFA) of the ESC. Eur Heart J 2012;33:1787-847. 
[3] Roubille F, Lattuca B, Busseuil D, Leclercq F, Davy JM, Rheaume E, et al. Is ivabradine suitable to control undesirable tachycardia induced by dobutamine in cardiogenic shock treatment? Med Hypotheses 2013;81:202-6.

[4] Roubille F, Tardif JC. New therapeutic targets in cardiology: heart failure and arrhythmia: HCN channels. Circulation 2013;127:1986-96.

[5] Ragueneau I, Laveille C, Jochemsen R, Resplandy G, Funck-Brentano C, Jaillon P. Pharmacokinetic-pharmacodynamic modeling of the effects of ivabradine, a direct sinus node inhibitor, on heart rate in healthy volunteers. Clin Pharmacol Ther 1998;64:192-203.

[6] Manz M, Reuter M, Lauck G, Omran H, Jung W. A single intravenous dose of ivabradine, a novel I(f) inhibitor, lowers heart rate but does not depress left ventricular function in patients with left ventricular dysfunction. Cardiology 2003;100: 149-55.

[7] Simon L, Ghaleh B, Puybasset L, Giudicelli JF, Berdeaux A. Coronary and hemodynamic effects of S 16257, a new bradycardic agent, in resting and exercising conscious dogs. J Pharmacol Exp Ther 1995;275:659-66.

[8] Swedberg K, Komajda M, Bohm M, Borer JS, Ford I, Dubost-Brama A, et al. Ivabradine and outcomes in chronic heart failure (SHIFT): a randomised placebo-controlled study. Lancet 2010;376:875-85.

[9] Tan LB, Schlosshan D, Hall AS. Cardiac functional benefits of ivabradine therapy in patients with severe heart failure. Int J Cardiol 2013;165:389-90.

[10] De Ferrari GM, Mazzuero A, Agnesina L, Bertoletti A, Lettino M, Campana C, et al. Favourable effects of heart rate reduction with intravenous administration of ivabradine in patients with advanced heart failure. Eur J Heart Fail 2008;10:550-5.

[11] Tardif JC, O'Meara E, Komajda M, Bohm M, Borer JS, Ford I, et al. Effects of selective heart rate reduction with ivabradine on left ventricular remodelling and function: results from the SHIFT echocardiography substudy. Eur Heart J 2011;32:2507-15.

[12] Gallet R, Ternacle J, Damy T, Guendouz S, Bremont C, Seemann A, et al. Hemodynamic effects of Ivabradine in addition to dobutamine in patients with severe systolic dysfunction. Int J Cardiol 2014;176(2):450-5.
[13] Nuding S, Ebelt H, Hoke RS, Krummenerl A, Wienke A, Muller-Werdan U, et al. Reducing elevated heart rate in patients with multiple organ dysfunction syndrome by the I (f) (funny channel current) inhibitor ivabradine: MODI (f)Y trial. Clin Res Cardiol 2011;100:915-23.

Benoit Lattuca

Cardiology Department, Montpellier University Hospital, Montpellier, France

François Roubille*

Cardiology Department, Montpellier University Hospital, Montpellier, France Inserm U1046, Montpellier, France

${ }^{*}$ Corresponding author at: Cardiology Department, Hôpital Arnaud de Villeneuve, CHU de Montpellier, UFR de Médecine,

Université Montpellier 1, 371, Avenue du Doyen Gaston Giraud, 34295 Montpellier Cedex 05, France. Tel.: + 337880141 36;

fax: + 33467336230

E-mail address: francois.roubille@gmail.com. 